\title{
Semiconductor Conference
}

Welcome

On behalf of the University of Michigan, I would like to welcome this, the Fourth Conference on Modulated Semiconductor Structures, to our campus.

We are both pleased and honored to be able to host such an important gathering of scientists from throughout the world.

The extraordinary advances made in this important interdisciplinary research area have revolutionized electronics and optics.

\section{Personal Involvement}

It was $\mathbf{2 5}$ years ago when I received my own degree in electrical engineering, and at that time, transistor-based devices were just becoming popular and the integrated circuit was starting to appear.

But we never dreamed what remarkable devices would be made possible by the merging of solid state physics, surface physics, and powerful new fabrication methods such as molecular beam epitaxy.

My own exposure to this field first

came rougly a decade ago, shortly after I had become dean of our engineering school, when we were approached by two groups of engineers and physicists, both seeking our support for the acquisition of MBE machines.

I should confess that my first reaction was one of shock... the thought of machines at $\$ 500 \mathrm{~K}$ a pop was quite unnerving.

\section{UM Effort}

And, yet, within a few short years we were committing to the development of new programs and facilities aimed at this fascinating new science.

Some of these facilities are close by in our Physics Department.

And two miles away on our North Campus, we recently brought on line one of this nation's largest and most complete solid state electronics and optics laboratories, much of it dedicated to the sophisticated fabrication and 
diagnostic techniques associated with modulated semiconductor structures.

I am certain that Professors Battacharya or Haddad would be delighted to show off their new facilities.

(Incidently, when I was Dean I used to refer to these facilities

as our "black hole"...since millions of dollars kept going into their development...but little light came out! Today it is clear that a great deal is emerging... and the investment has paid off handsomely!)

Art Fair...

As many of you may be aware, Ann Arbor is regarded by many as the prototype of university communities in our nation...

Cities which draw their excitement and intellectual vitality from the dominant presence of a large, comprehensive, research university.

Indeed, throughout most of its history, the University of Michigan has been regarded as the flagship of public universities in America.

At this time of the year, most of our 35,000 students are gone on summer break.

But this week they will be replaced by hundreds of thousands

of visitors to the Ann Arbor Art Fair which starts on Wednesday.

In recent years, this has become one of the largest art fairs

in the country, and while the crowds may complicate your activities a bit, the activities surrounding the fair will add a good deal of excitement.

Final Comments

Once again, welcome to the University and to Ann Arbor. We are honored to have you as our guests. And we hope that you will have a fascinating and rewarding

conference. 